\title{
Mathematical Modeling, Moisture Diffusion, Energy consumption and Efficiency of Thin Layer Drying of Potato Slices
}

\section{Hosain Darvishi ${ }^{1 *}$, Abbas Rezaie Asl ${ }^{2}$, Ali Asghari², Gholamhassan Najafi ${ }^{3}$ and Heshmat Allah Gazori ${ }^{1}$}

${ }^{1}$ Department of Engineering, Shahre Ray Branch, Islamic Azad University, Tehran, Iran

${ }^{2}$ Department of Agricultural Machinery Mechanics, Agricultural Sciences \& Natural Resources University of Gorgan, Gorgan, Iran

${ }^{3}$ Department of Agricultural Machinery Mechanics, Faculty of Agriculture, Tarbiat Modares University, Tehran, Iran

\begin{abstract}
In this research, drying characteristics, energy requirement and drying efficiency for microwave drying of potato slices were reported. The drying experiments were carried out at 200, 250, 300, 350, 400, 450 and $500 \mathrm{~W}$ with slice thickness of $5 \mathrm{~mm}$. In this study, measured values were compared with predicted values obtained from Page's thin layer drying semi-empirical model according to $\mathrm{R}^{2}, \mathrm{X}^{2}$ and RMSE. The increase in microwave power significantly reduced the drying time from 9.5 to $3.25 \mathrm{~min}$ of the potato slices. Experimental drying curves showed only a falling drying rate period. A third order polynomial relationship was found to correlate the effective moisture diffusivity $\left(D_{\text {eff }}\right)$ with moisture content. The values of drying rate constant $(k)$ and $D_{\text {eff }}$ increased from 0.105 to $0.322(1 / \mathrm{min})$ and $1.013 \times 10^{-8}$ to $3.799 \times 10^{-8} \mathrm{~m}^{2} / \mathrm{s}$ with the increase of microwave power level, respectively. Also, the effective moisture diffusivity increased with decrease in moisture content of samples. The activation energy for the moisture diffusion was determined to be $14.945 \mathrm{~W} / \mathrm{g}$. Drying efficiency increased with increase in microwave power and moisture content. The minimum and the maximum specific energy consumption and drying efficiency for drying of potato slices were determined as $4.645(\mathrm{MJ} / \mathrm{kg}$ water) and $48.59 \%$ for $500 \mathrm{~W}$ and $5.882(\mathrm{MJ} / \mathrm{kg}$ water) and $38.37 \%$ for 300 $\mathrm{W}$, respectively.
\end{abstract}

Keywords: Microwave drying; Modeling; Moisture diffusivity; Energy consumption; Drying efficiency; Potato slice

\section{Introduction}

Potatoes represent the fourth most important vegetable crop for human nutrition in the world and an important source of carbohydrate for people in Asia [1]. Potato is a food with high initial water content and approximately $12 \%$ are dehydrated products [1-2]. Potato drying is a highly energy-consuming process. Also, the drying methods have significant effects on the dried potato quality such as nutritional values, color, shrinkage and other organoleptic properties. So far, many works have been performed to study hot air, tray dryer with and without air circulation, fluidized bed, and superheated steam drying of potato pieces of various shapes [1-15]. But commonly used hot air techniques are limited by high energy consumption, long drying times, low energy efficiency and high costs, which is not desirable for the food industry. Due to these difficulties, more rapid, safe and controllable drying methods are required. Also, it is necessary to dry the product with minimum cost, energy and time. In microwave drying, drying time is shortened due to quick absorption of energy by water molecules, causes rapid evaporation of water, resulting in high drying rates of the food [16-18].

One of the most important aspects of drying technology is the modeling of the drying process. There are various studies at the research level about drying of vegetables. For example; Bakal et al. [4] and Senadeera et al. [5] reported that the Page model best described the drying behaviour of potato. As little research has been performed effect of microwave power on energy consumption and drying efficiency in microwave drying method [7]. The present research is focused on this issue. The aim of this study was to (i) describe the influence of microwave output power on drying kinetics and energy efficiency, and (ii) compare the measured findings obtained during the drying of potato with the predicted values obtained with Page's semi-empirical equation for the purpose of simulation and scaling up of the process.

\section{Materials and Methods}

\section{Material}

Potatoes were purchased from a local market, in Tehran, Iran, and were stored in the refrigerator at temperature of $4 \pm 1^{\circ} \mathrm{C}$ until the experiments were carried out. The potatoes were washed with tap water, peeled and cut into slices with thickness of $5 \mathrm{~mm}$. The initial moisture content of the samples found about $75 \pm 1.5 \%$ (w.b.), and was determined by drying in an air convection oven at $103 \pm 1{ }^{\circ} \mathrm{C}$ till the weight did not change any more [14].

\section{Experimental procedure}

A domestic microwave oven (M945, Samsung Electronics Ins) with maximum output of $1000 \mathrm{~W}$ at $2450 \mathrm{MHz}$ was used for the drying experiments. The oven has a fan for air flow in drying chamber and cooling of magnetron. The moisture from drying chamber was removed with this fan by passing it through the openings on the right side of the oven wall to the outer atmosphere. The microwave dryer was operated by a control terminal which could control both microwave power level and emission time. For measuring the weight of the samples during experimentation without taking them out of the oven, the tray with sample was suspended on the balance with a nylon wire through a

*Corresponding author: H. Darvishi, Department of Engineering, Shahre Ray Branch, Islamic Azad University, Tehran, Iran, Tel: ++989382279329; Fax: ++98(21) 44196524; E-mail: Hosaindarvishi@gmail.com

Received July 10, 2012; Accepted January 15, 2012; Published January 25, 2013

Citation: Darvishi H, Asl AR, Asghari A, Najafi G, Gazori HA (2013) Mathematica Modeling, Moisture Diffusion, Energy consumption and Efficiency of Thin Layer Drying of Potato Slices. J Food Process Technol 4: 215. doi:10.4172/2157. 7110.1000215

Copyright: (c) 2013 Darvishi H, et al. This is an open-access article distributed under the terms of the Creative Commons Attribution License, which permits unrestricted use, distribution, and reproduction in any medium, provided the original author and source are credited. 
ventilation hole in the center of chamber ceiling. Experiments were performed at five microwave powers of $200,250,300,350,400,450$ and $500 \mathrm{~W}$. The moisture losses of samples were recorded at $15 \mathrm{~s}$ intervals during the drying process by a digital balance (GF-600, A and $\mathrm{D}$, Japan) and an accuracy of $\pm 0.01 \mathrm{~g}$. Drying was carried out until the final moisture content reaches to a level less than $4 \%$ (w.b.). All measurements were carried out in triplicate.

\section{Data analysis}

The moisture ratio (MR) was calculated using the following equation:

$$
M R=\frac{X_{t}-X_{e}}{X_{0}-X_{e}}
$$

where, $\mathrm{MR}$ is the moisture ratio (dimensionless); $\mathrm{X}_{\mathrm{t}}, \mathrm{X}_{\mathrm{e}}$ and $\mathrm{X}_{0}$ are the moisture content at any time, the equilibrium moisture content, the initial moisture content ( $\mathrm{kg}$ water $/ \mathrm{kg}$ dry mater), respectively. The values of $X_{e}$ are relatively small compared to $X_{t}$ and $X_{0}$, hence the error involved in the simplification by assuming that $\mathrm{X}_{\mathrm{e}}$ is equal to zero is negligible.

The Page's model is an empirical modification of the simple exponential model to overcome its shortcomings. It was successfully used to describe the drying characteristics of a variety of biological materials. Therefore, the semi-empirical Page's equation (Eq. (2)) was used to describe the thin layer drying kinetics of samples [4-5]:

$$
M R=\frac{X_{t}}{X_{0}}=\exp \left(-k t^{n}\right)
$$

where $\mathrm{k}$ is the drying constant $(1 / \mathrm{min})$; and $\mathrm{n}$ is the dimensionless exponent. Statistical test using the coefficient of determination $\left(\mathrm{R}^{2}\right)$, reduced chi-square $\left(\chi^{2}\right)$ and root mean square error (RMSE) were calculated to evaluate the goodness of fit of Page's model. The reduced $\chi^{2}$ and RMSE were calculated according to the following equation [14]:

$$
\begin{aligned}
& \chi^{2}=\frac{\sum_{i=1}^{N}\left(M R_{\text {pre }, i}-M R_{\text {exp }, i}\right)}{N-z} \\
& R M S E=\left(\frac{\sum_{i=1}^{N}\left(M R_{\text {pre }, i}-M R_{\text {exp }, i}\right)^{2}}{N}\right)^{\frac{1}{2}}
\end{aligned}
$$

where $\mathrm{MR}_{\exp }$ is the experimental dimensionless moisture ratio, $\mathrm{MR}_{\mathrm{pre}}$ is the predicted dimensionless moisture ratio by Page model, $\mathrm{N}$ is the number of experimental data points, and $\mathrm{z}$ is the number of parameters in model. The model is said to be good if $\mathrm{R}^{2}$ value is high and, $\chi^{2}$ and RMSE values are low.

Drying rate was defined as:

$$
D R=\frac{X_{t+\Delta t}-X_{t}}{\Delta t}
$$

where $\mathrm{X}_{\mathrm{t}+\Delta \mathrm{t}}$ is moisture content at time $\mathrm{t}+\Delta \mathrm{t}$ (kg water/kg dry mater), $\mathrm{t}$ is the time $(\mathrm{min})$ and $\mathrm{DR}$ is the drying rate $(\mathrm{kg}$ water $/ \mathrm{kg}$ dry mater. $\min )$.

Moisture diffusivity: Fick's second law of diffusion equation, symbolized as a mass-diffusion equation for drying agricultural products in a falling rate period, is shown in the following equation:

$$
\frac{\partial M}{\partial t}=D_{e f f} \frac{\partial^{2} M}{\partial x^{2}}
$$

By using appropriate initial and boundary conditions, Crank [19] gave the analytical solutions for various geometries and the solution for slab object with constant diffusivity is given as:

$$
M R=\frac{8}{\pi^{2}} \sum_{n=0}^{\infty} \frac{1}{(2 n+1)^{2}} \exp \left(-(2 n+1)^{2} \pi^{2} \frac{D_{e f f} t}{L^{2}}\right)
$$

where $\mathrm{D}_{\text {eff }}$ is the effective diffusivity $\left(\mathrm{m}^{2} / \mathrm{s}\right)$, and $\mathrm{L}$ is the $\mathrm{L}$ is the thickness of samples $(\mathrm{m}), \mathrm{n}$ is a positive integer.

The Eq. (7) can be simplified by taking the first term of Eq. (8):

$$
M R=\frac{8}{\pi^{2}} \exp \left(-\frac{\pi^{2} D_{e f f} t}{L^{2}}\right)
$$

Eq. (8) is evaluated numerically for Fourier number, $\mathrm{F}_{0}=\mathrm{D}_{\text {eff }} \times \mathrm{t} / \mathrm{L}^{2}$, for diffusion and can be rewritten as Eq. (9) can be rewritten as:

$$
\begin{aligned}
& M R=\frac{8}{\pi^{2}} \exp \left(-\pi^{2} F_{0}\right) \\
& \text { Thus: } \\
& F_{0}=-0.101 \ln (M R)-0.0213
\end{aligned}
$$

The effective moisture diffusivity was calculated using Eq. (11) as:

$$
D_{e f f}=\frac{F_{0}}{\left(\frac{t}{L^{2}}\right)}
$$

The average moisture diffusion coefficients are typically determined by plotting experimental drying data in terms of $\ln (\mathrm{MR})$ versus drying time $(t)$, because the plot gives a straight line with a slope as $\pi^{2} \mathrm{D}_{\text {eff }} / \mathrm{L}^{2}$.

Activation energy: In as much as temperature is not precisely measurable inside the microwave drier, the activation energy is found as modified from the revised Arehnious equation. In this method it is assumed as related to effective moisture diffusion and the ratio of microwave output power to sample weight $(\mathrm{m} / \mathrm{p})$ instead of to air temperature. Then Equation (9) can be effectively used as follows [1617]:

$$
D_{\text {eff }}=D_{0} \exp \left(-\frac{E_{a} m}{P}\right)
$$

where $E_{a}$ is the activation energy (W/g), $m$ is the mass of raw sample $(\mathrm{g}), \mathrm{D}_{0}$ is the pre-exponential factor $\left(\mathrm{m}^{2} / \mathrm{s}\right)$ and $\mathrm{P}$ is the microwave power (W).

Energy consumption and efficiency: The energy consumption of microwave could be calculated as follows:

$$
E_{c}=P \times t
$$

The specific energy consumption is calculated using Eq. (14) [16].

$$
E_{s}=\frac{P \times t}{m_{w}}
$$

where $E_{s}$ is the specific energy consumption $(\mathrm{J} / \mathrm{kg}$ water); $\mathrm{P}$ is the microwave power $(\mathrm{W})$; and $\mathrm{m}_{\mathrm{w}}$ is the total mass of evaporated water $(\mathrm{kg})$.

The microwave drying efficiency was calculated as the ratio of heat energy utilised for evaporating water from the sample to the heat supplied by the dryer [16-18].

$$
\eta=\frac{m_{w} \times \lambda_{w}}{P \times t}
$$

where $\eta$ is the microwave drying efficiency (\%) and $\lambda_{w}$ is the latent heat of vaporisation of water. 


\section{Results and Discussion}

The moisture content versus drying time curves for microwave drying of potato slice samples as affected by various microwave powers are shown in figure 1 . The time required to dry potato samples from initial moisture content of $75 \pm 1.5 \%$ (w.b.) to the final moisture content of $4 \pm 1 \%$ (w.b.) was $9.5,8.5,6.5,5.75,5,3.75$ and $3.25 \mathrm{~min}$ at $200,250,300,350,400,450$ and $500 \mathrm{~W}$, respectively. Drying microwave power had an important effect on drying time. The results indicated that mass transfer within the sample was more rapidly during higher microwave power heating because more heat was generated within the sample creating a large vapor pressure difference between the center and the surface of the product due to characteristic microwave volumetric heating.

The moisture content data obtained from the drying experiments was fitted to the Page model. The statistical results from the models such as $\mathrm{R}^{2}, \chi^{2}$ and RMSE values are shown in table 1 . As it is seen, the $\mathrm{R}^{2}, \chi^{2}$ and RMSE values range from 0.996 to $0.999,0.00018$ to 0.00023 and 0.01294 to 0.01477 , respectively. The high values of $R^{2}$ and the low values of $\chi^{2}$ and RMSE indicate in the Page model a good fit. Based on the multiple regression analysis, the Page model, the constants and coefficients were as follows:

$$
\begin{aligned}
& k=0.044 \exp (0.0041 P) R^{2}=0.961 \\
& n=1.5006-0.0015 P+10^{-6} P^{2} R^{2}=0.945
\end{aligned}
$$

Thus:

$$
M R=\exp \left(-0.044 \exp (0.0041 P) t^{1.5006-0.0015 P+5 \times 10^{-6} P^{2}}\right)
$$

It is determined that the value of the drying constant $\mathrm{k}$ increased with the increase in microwave power. This data points out that

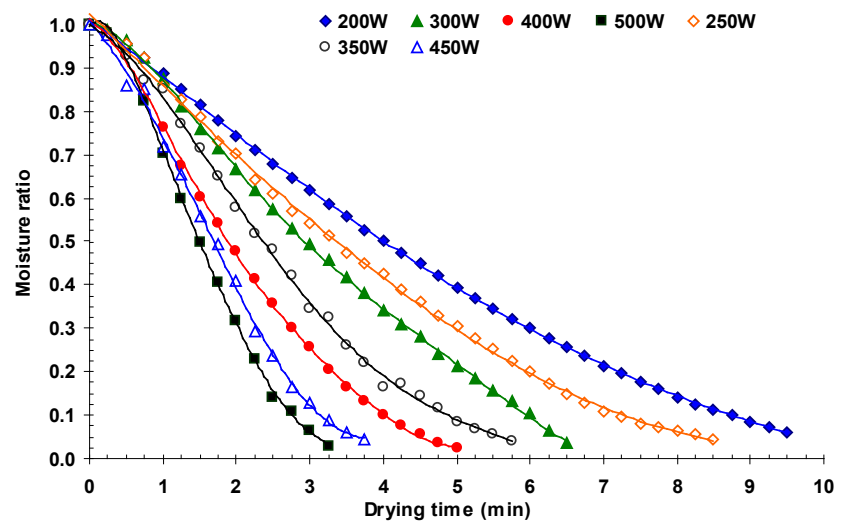

Figure 1: The variation of the moisture ratio with drying time at various microwave powers.

\begin{tabular}{|l|l|l|l|l|}
\hline $\mathbf{P}(\mathbf{W})$ & Model constants & $\mathbf{R}^{2}$ & $\mathbf{X}^{2}$ & RMSE \\
\hline 200 & $\mathrm{k}=0.105, \mathrm{n}=1.383$ & 0.997 & 0.00023 & 0.01477 \\
\hline 250 & $\mathrm{k}=0.125 ; \mathrm{n}=1.412$ & 0.997 & 0.00041 & 0.01972 \\
\hline 300 & $\mathrm{k}=0.130, \mathrm{n}=1.457$ & 0.997 & 0.00032 & 0.01742 \\
\hline 350 & $\mathrm{k}=0.174 ; \mathrm{n}=1.624$ & 0.999 & 0.00056 & 0.02269 \\
\hline 400 & $\mathrm{k}=0.256, \mathrm{n}=1.564$ & 0.998 & 0.00018 & 0.01294 \\
\hline 450 & $\mathrm{k}=0.289 ; \mathrm{n}=1.762$ & 0.996 & 0.00048 & 0.02069 \\
\hline 500 & $\mathrm{k}=0.322, \mathrm{n}=1.922$ & 0.998 & 0.00023 & 0.01404 \\
\hline
\end{tabular}

Table 1: Results of statistical analysis on the modeling (Page's model) of moisture content and drying time for potato slices. following the increase in microwave output power, drying curve becomes steeper, indicating faster drying of the product. Figure 2 shows the comparison between experimental moisture ratio at different drying powers and that predicted by the Page's model. As can be seen, the dots in figure 2 are closely banding around at a $45^{\circ}$ straight line - a very good agreement between calculated and experimental data, which indicates that the Midilli model could adequately describe the drying behavior of potato slices.

Figure 3 shows how the drying rate of potato samples was changed with increased drying time under various drying conditions. The drying rates increased with the increasing microwave power levels. The moisture content of the material was very high during the initial phase of the drying which resulted in a higher absorption of microwave power and higher drying rates due to the higher moisture diffusion. As the drying progressed, the loss of moisture in the product caused a decrease in the absorption of microwave power and resulted in a fall in the drying rate. Similar results were obtained by several researchers in other foods such as tomato pomace [20], apple pomace [21], Gundelia tournefortii [22], okra [23], peach [24], parsley [18,25], garlic cloves [26], spinach [27], fish and shrimp [16,28].

\section{Effective moisture diffusivity}

Variation in effective moisture diffusivity of potato slices with moisture content at different microwave power levels is shown in figure 4. The effective moisture diffusivity increased with decrease in moisture content. However, the moisture diffusivity further was higher at any level of moisture content at higher microwave power level, resulting into shorter drying time. This may indicate that as moisture content decreased, the permeability to vapour increased, provided the pore structure remained open. The temperature of the product rises rapidly in the initial stages of drying, due to more absorption of microwave heat, as the product has a high loss factor at higher moisture content. This increases the water vapour pressure inside the pores and results in pressure induced opening of pores. In the first stage of drying, liquid diffusion of moisture could be the main mechanism of moisture transport. As drying progressed further, vapour diffusion could have been the dominant mode of moisture diffusion in the latter part of drying. Pickles [29], Sharma and Prasad [30]; Reyes et al. [6], Caglar et al. [31] and Sharma et al. [32] also reported similar trend in the variation in the moisture diffusivity with moisture content.

A third order polynomial relationship was found to correlate the effective moisture diffusivity with corresponding moisture content of samples and is given by Eq. (19)

$$
D_{\text {eff }}=\left(A+B X+C X^{2}+D X^{3}\right) \times 10^{-8}
$$

where $\mathrm{A}, \mathrm{B}, \mathrm{C}$ and $\mathrm{D}$ is the constants of regression, and $\mathrm{X}$ is moisture content (d.b.). Regression constants for microwave drying of potato slices under different powers are presented in table 2 . The high values of $\mathrm{R}^{2}$ are indicative of good fitness of empirical relationship to represent the variation in effective moisture diffusivity with moisture content of potato slices.

The variation in $\ln (\mathrm{MR})$ and drying time $(\mathrm{t})$ for different powers have been plotted in figure 5 to obtain the slope $S$ (Eq. 9) which can give the average effective moisture diffusivity $\left(D_{\text {eff }}\right)$. The determined average values of $\mathrm{D}_{\text {eff }}$ for different microwave powers are given in table 3 . The values lie within the general range of $10^{-9}-10^{-11} \mathrm{~m}^{2} / \mathrm{s}$ for food materials. It can be seen that the values of $\mathrm{D}_{\text {eff }}$ increased with increasing microwave power. This might be explained by the increased heating energy, which 


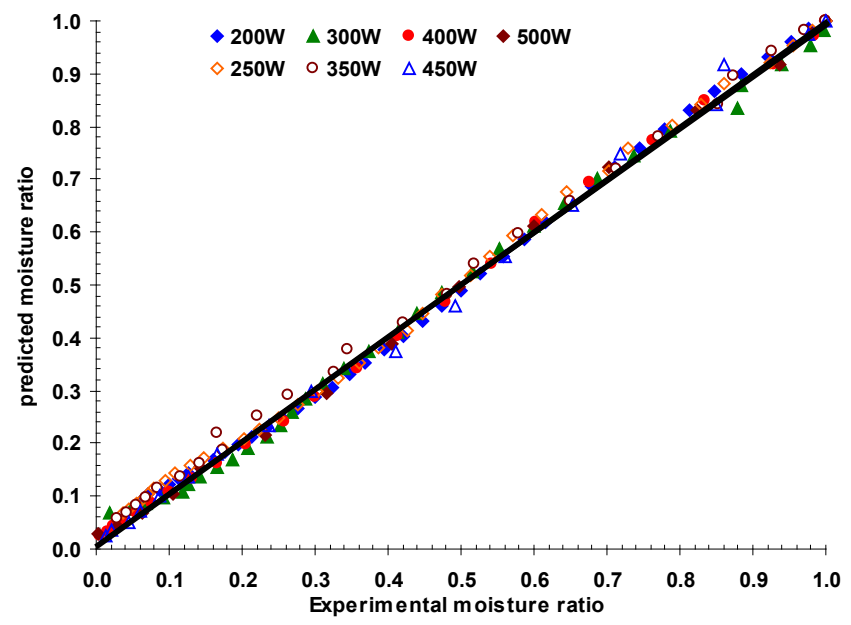

Figure 2: Comparison of experimental and calculated dimensionless moisture content values by the Page's model.

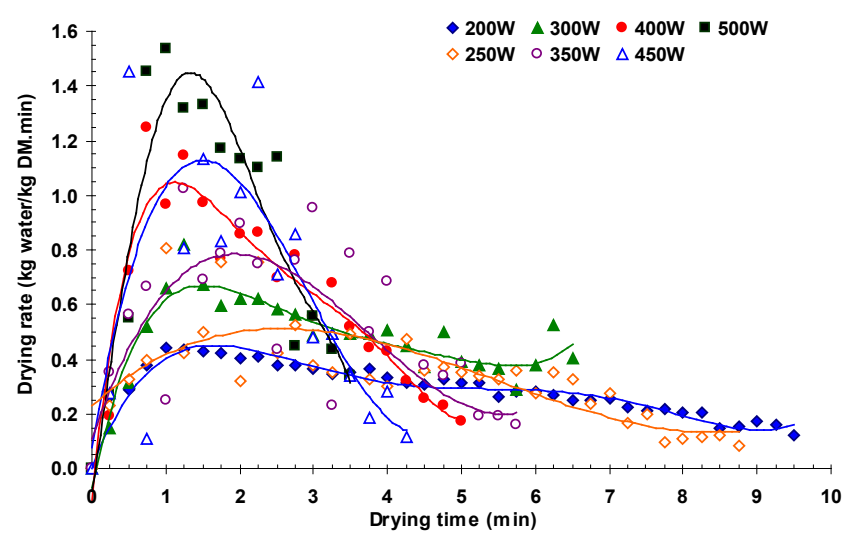

Figure 3: Variation of drying rate with time for the potato slices.

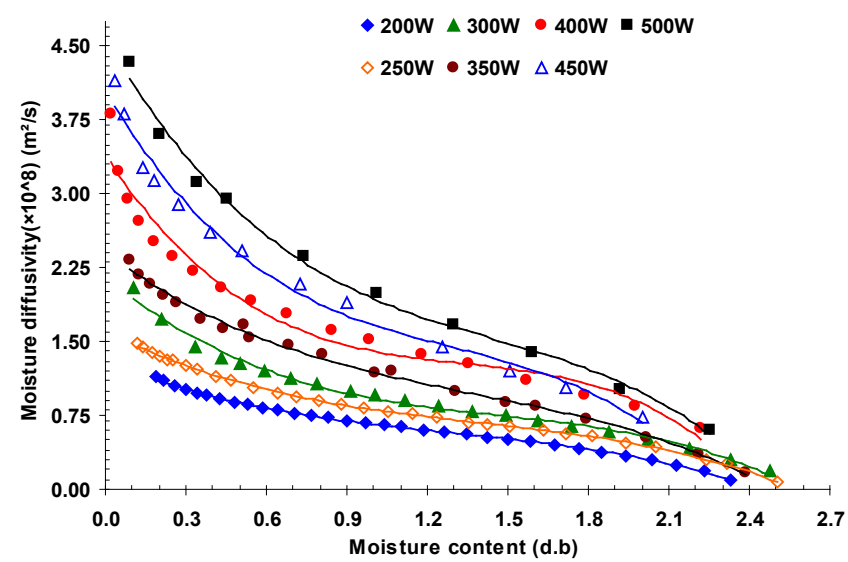

Figure 4: Variation in effective moisture diffusivity with moisture content at different microwave powers.

would increase the activity of the water molecules leading to higher moisture diffusivity when samples were dried at higher microwave power. $5.612 \times 10^{-9}$ to $1.317 \times 10^{-8} \mathrm{~m}^{2} / \mathrm{s}$ for fluidized bed drying of potatoes [4], $4.606 \times 10^{-6}$ to $7.065 \times 10^{-6} \mathrm{~m}^{2} / \mathrm{s}$ freeze-drying of sweet potato cubes with far-infrared [15], $3.17 \times 10^{-7}$ to $15.45 \times 10^{-7} \mathrm{~m}^{2} / \mathrm{s}$ for thin-layer drying of potato slices in length of continuous band dryer [14], and $2.90 \times 10^{-8}$ to $4.88 \times 10^{-8} \mathrm{~m}^{2} / \mathrm{s}, 7.04 \times 10^{-8}$ to $24.22 \times 10^{-8} \mathrm{~m}^{2} / \mathrm{s}$, and $3.15 \times 10^{-8}$ to $5.36 \times 10^{-8} \mathrm{~m}^{2} / \mathrm{s}$ for convective, microwave and combined drying of potato cylinders, respectively [7]. The differences between the results can be explained by effect of method drying, type, composition, and tissue characteristics of the potatoes and the proposed model used for calculation.

After evaluation of the data, to determine the relationship between drying rate constant and effective moisture diffusivity, linear model, Eq. (20), which was derived by Ozbek and Dadali [17] were used with the coefficient of determination of $\left(\mathrm{R}^{2}\right)$ statistical value of 0.974 . The value of constant (A) was obtained as $8.77 \times 10^{6}\left(\mathrm{~s} / \mathrm{min} . \mathrm{m}^{2}\right)$. The fitness of the data with Eq. (10) was illustrated in figure 6.

$$
k=Y \cdot D_{e f f}
$$

\begin{tabular}{|l|l|}
\hline $\mathbf{P}(\mathbf{W})$ & Effective diffusivity $\left(\mathbf{m}^{2} / \mathbf{s}\right)$ \\
\hline 200 & $1.013( \pm 0.053) \times 10^{-8}$ \\
\hline 250 & $1.317( \pm 0.094) \times 10^{-8}$ \\
\hline 300 & $1.520( \pm 0.121) \times 10^{-8}$ \\
\hline 350 & $2.127( \pm 0.085) \times 10^{-8}$ \\
\hline 400 & $2.659( \pm 0.183) \times 10^{-8}$ \\
\hline 450 & $3.343( \pm 0.203) \times 10^{-8}$ \\
\hline 500 & $3.799( \pm 0.163) \times 10^{-8}$ \\
\hline
\end{tabular}

Table 2: Average effective diffusivity values for microwave drying of potato slices.

\begin{tabular}{|l|l|l|l|l|l|}
\hline $\mathbf{P}(\mathbf{W})$ & A & B & C & D & R2 \\
\hline 200 & 1.3075 & -1.1399 & 0.658 & -0.1679 & 0.999 \\
\hline 250 & 1.6120 & -1.4102 & 0.7967 & -0.1910 & 0.999 \\
\hline 300 & 2.1517 & -2.2570 & 1.3268 & -0.2998 & 0.992 \\
\hline 350 & 2.4086 & -2.0564 & 1.099 & -0.2658 & 0.995 \\
\hline 400 & 3.3906 & -4.179 & 2.9204 & -0.7306 & 0.965 \\
\hline 450 & 4.0522 & -4.6663 & 3.0721 & -0.7915 & 0.985 \\
\hline 500 & 4.5821 & -4.7721 & 2.7606 & -0.6376 & 0.994 \\
\hline
\end{tabular}

Table 3: Regression coefficients of effective moisture diffusivity for different microwave powers.

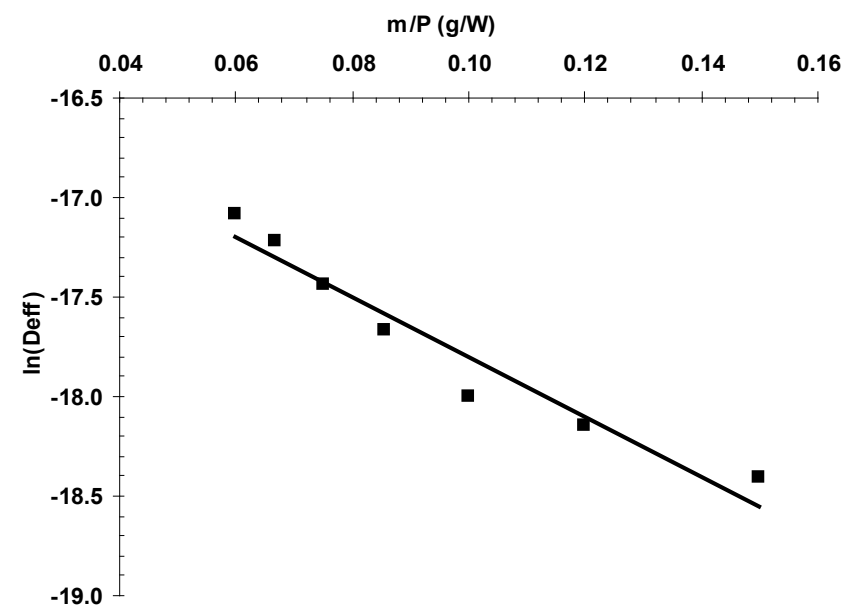

Figure 5: Relationship between $D_{\text {eff }}$ and sample weight/microwave operating power for potato slices. 


\section{Activation energy}

The activation energy was calculated by plotting the natural logarithm of $\mathrm{D}_{\text {eff }}$ versus sample amount/power $(\mathrm{m} / \mathrm{P})$ as presented in figure 7. The plot was found to be a straight line in the range of microwave power studied, indicating Arrhenius dependence. Then, the dependence of the effective diffusivity of potato samples on the microwave power can be represented by the following equation:

$$
D_{\text {eff }}=8.29 \times 10^{-8} \exp \left(-14.945 \frac{\mathrm{m}}{P}\right) R^{2}=0.939
$$

The activation energy for potato samples was found to be 14.945 $\mathrm{W} / \mathrm{g}$. This value is higher than that corresponding to okra $(5.54 \mathrm{~W} / \mathrm{g})$ [23], mint leaves (12.284 W/g) [17], sardine fish (14.1383 W/g) [16], shrimp (12.834 W/g) [28], pandanus leaves (13.6 W/g) [33], but lower than the value obtained for sweet and sour pomegranate (16.675 and $24.222 \mathrm{~W} / \mathrm{g}$ ) [34]. The lower activation energy translates to higher moisture diffusivity in the drying process [30].

\section{Energy consumption and efficiency}

Figure 8 shows the variation of energy efficiency whit drying time

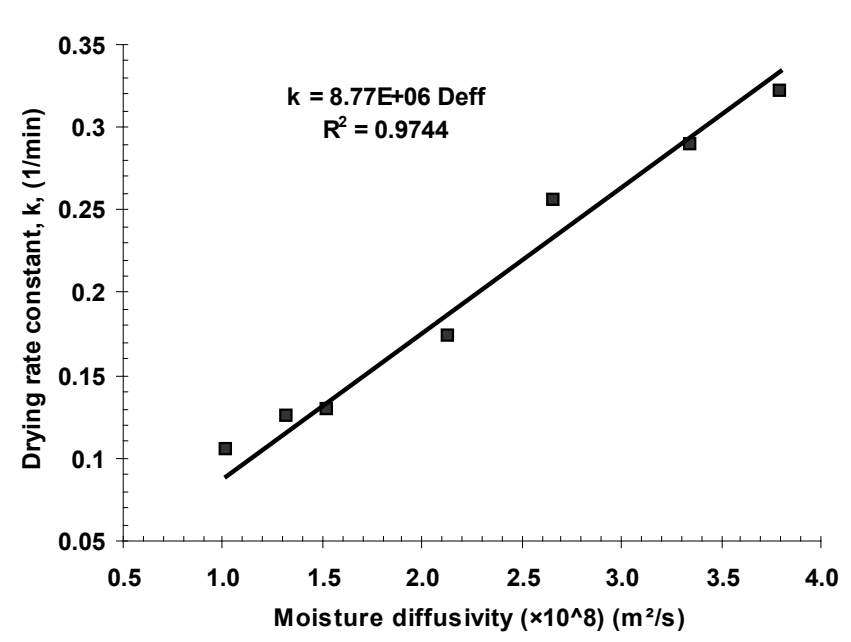

Figure 6: The relationship between the values of drying rate constant and effective moisture diffusivity.

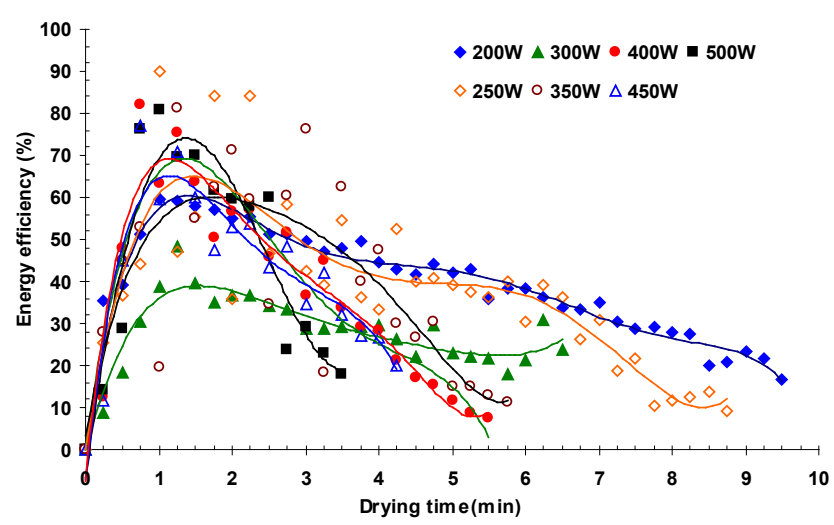

Figure 7: Energy efficiency versus drying time for microwave drying of potato samples.

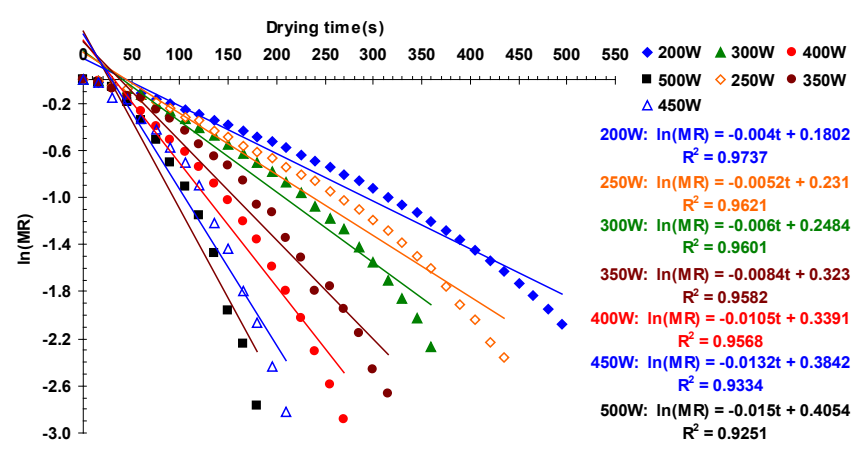

Figure 8: Variation in In (MR) and drying time (in seconds) for potato slices dried at different microwave powers.
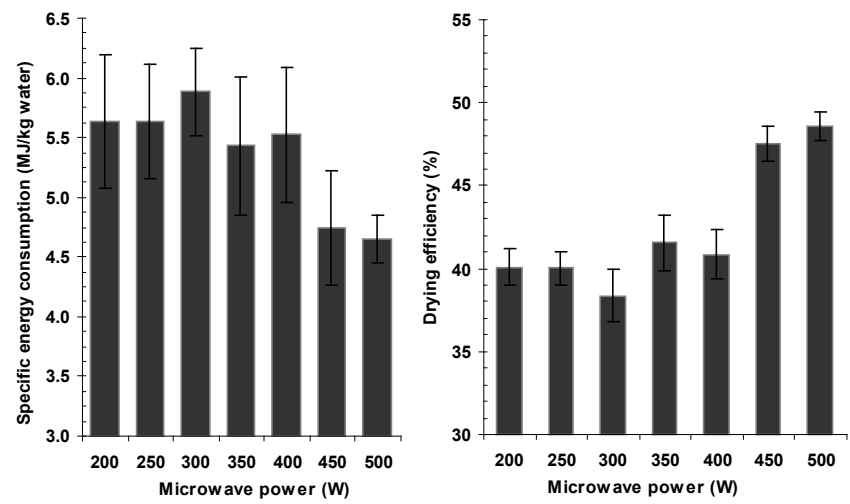

Figure 9: Average of specific energy consumption and drying efficiency for the potato slices at different microwave powers

for microwave drying of potato samples. The energy efficiency was very high during the initial phase of the drying which resulted in a higher absorption of microwave power. Following moisture reduction, the energy absorbed by the product decreased and reflected power increased. The best result with regard to energy efficiency was obtained from $250 \mathrm{~W}$ microwave power levels among all microwave power. Similar trends were also observed by Soysal et al. [18] and Darvishi et al. [16].

The average energy needed for drying $1 \mathrm{~kg}$ of samples can be seen from figure 9. The values ranged from 4.645 to $5.882 \mathrm{MJ} / \mathrm{kg}$ water. Average energy efficiency of potato slice samples ranged from $38.37 \%$ to $48.59 \%$ for the output microwave power. The minimum specific energy consumption $(4.645 \mathrm{MJ} / \mathrm{kg})$ obtained at microwave power of $500 \mathrm{~W}$.

\section{Conclusion}

The effect of microwave drying technique on moisture content, drying rate, drying time, effective moisture diffusivity, energy consumption and drying efficiency of potato slices were investigated. The changes of moisture content have been described by using Page's model. The value of the drying rate constant, $k$, increased with the increase in microwave output power. Effective moisture diffusivity depends on the moisture content, and increases with decrease in moisture content. The values of effective diffusivity for microwave drying of potato ranged from $1.013 \times 10^{-8}$ to $3.799 \times 10^{-8} \mathrm{~m}^{2} / \mathrm{s}$ and activation energy was found $14.945 \mathrm{~W} / \mathrm{g}$. We concluded that $500 \mathrm{~W}$ is 
Citation: Darvishi H, Asl AR, Asghari A, Najafi G, Gazori HA (2013) Mathematical Modeling, Moisture Diffusion, Energy consumption and Efficiency of Thin Layer Drying of Potato Slices. J Food Process Technol 4: 215. doi:10.4172/2157-7110.1000215

the optimum microwave power level in the microwave drying of potato with respect to drying time, specific energy consumption and drying efficiency. At the later stages of the drying process, drying efficiency values decreased considerably to a value as low as $10 \%$.

\section{References}

1. Miranda M, Jose A (2006) Structure and Texture Properties of Fried Potato Products. Food Rev Int 22: 173-201.

2. Akpinar EK, Midilli A, Bicer $Y$ (2005) Energy and exergy of potato drying process via cyclone type dryer. Energ Convers Manage 46: 2530-2552.

3. Doymaz I (2011) Thin-layer drying characteristics of sweet potato slices and mathematical modelling. Heat and Mass Transfer 47: 277-285.

4. Bakal SB, Sharma PG, Sonawane SP, Verma RC (2012) Kinetics of potato drying using fluidized bed dryer. J Food Sci Technol 49: 608-613.

5. Senadeera WW, Bhandari BR, Young G, Wijesinghe B (2003) Influence of shapes of selected vegetable materials on drying kinetics during fluidized bed drying. J Food Eng 58: 277-283.

6. Reyes A, Ceron S, Zuniga R, Moyano P (2007) A comparative study of microwave-assisted air drying of potato slices. Biosys Eng 98: 310-318.

7. McMinn WAM, Khraisheh MAM, Magee TRA (2003) Modelling the mass transfer during convective, microwave and combined microwave-convective drying of solid slabs and cylinders. Food Res Int 36: 977-983.

8. Krokida MK, Karathanos VT, Maroulis ZB, Marinos-Kouris D (2003) Drying kinetics of some vegetables. J Food Eng 59: 391-403.

9. Hatamipour MS, Kazemi HH, Nooralivand A, Nozarpoor A (2007) Drying Characteristics of Six Varieties of Sweet Potatoes in Different Dryers. Food Bioprod Process 85: 171-177.

10. Khraisheh MAM, McMinn WAM, Magee TRA (2004) Quality and structura changes in starchy foods during microwave and convective drying. Food Res Int 37: 497-503.

11. Leeratanarak N, Devahastin S, Chiewchan N(2006) Drying kinetics and quality of potato chips undergoing different drying techniques. J Food Eng 7: 635-643.

12. Pimpaporn P, Devahastin S, Chiewchan N (2007) Effects of combined pretreatments on drying kinetics and quality of potato chips undergoing lowpressure superheated steam drying. J Food Eng 81: 318-329.

13. Caixeta AT, Moreira R, Castell-Perez ME (2002) Impingement drying of potato chips. J Food Process Eng 25: 63-90.

14. Aghbashlo M, Kianmehr MH, Arabhosseini A (2009) Modeling of thin-layer drying of potato slices in length of continuous band dryer. Energ Convers Manag 50: 1348-1355.

15. Lin PY, Tsen JH, King VAE (2005) Effects of far-infrared radiation on the freeze-drying of sweet potato. J Food Eng 68: 249-255.

16. Darvishi H, Azadbakht M, Rezaieasl A, Farhang A (2012) Drying characteristics of sardine fish dried with microwave heating. Journal of the Saudi Society of Agricultural Sciences.

17. Ozbek B, Dadali G (2007) Thin-layer drying characteristics and modelling of mint leaves undergoing microwave treatment. J Food Eng 83: 541-549.

18. Soysal Y, Oztekin S, Eren O (2006) Microwave Drying of Parsley: Modelling, Kinetics, and Energy Aspects. Biosys Eng 93: 403-413.

19. Crank J (1975) The Mathematics of Diffusion. (2nd edn), Clarendon Press Oxford, UK.

20. Al-Harahsheh M, Al-Muhtaseb AH, Magee TRA (2009) Microwave drying kinetics of tomato pomace: Effect of osmotic dehydration. Chem Eng Process 48: 524-531.

21. Wang Z, Sun J, Chen F, Liao X, Hu X (2007) Mathematical modelling on thin layer microwave drying of apple pomace with and without hot air pre-drying. $J$ Food Eng 80: 536-544.

22. Evin D (2011) Thin layer drying kinetics of Gundelia tournefortii L. Food and Bioprod Process 90: 323-332.

23. Dadali G, Apar DK, Ozbek B (2007) Microwave Drying Kinetics of Okra. Dry Technol 25: 917-924.

24. Wang J, Sheng K (2006) Far-infrared and microwave drying of peach. LWTFood Sci Technol 39: 247-255.

25. Soysal Y (2004) Microwave drying characteristics of parsley. Biosys Eng 89 167-173.

26. Figiel A (2009) Drying kinetics and quality of vacuum-microwave dehydrated garlic cloves and slices. J Food Eng 94: 98-104.

27. Ozkan Al, Akbudak B, Akbudak N (2007) Microwave drying characteristics of spinach. J Food Eng 78: 577-583.

28. Darvishi H, Farhang A, Hazbavi E (2012) Mathematical Modeling of Thin-Layer Drying of Shrimp. GJSFR: Mathematics \& Decision Sciences 12: 83-90.

29. Pickles CA (2003) Drying kinetics of nickeliferous limonitic laterite ores. Miner Eng 16: 1327-1338.

30. Sharma GP, Prasad S (2004) Effective moisture diffusivity of garlic cloves undergoing microwave-convective drying. J Food Eng 65: 609-617.

31. Celma AR, Cuadros F, Lopez-Rodriguez F (2012) Convective drying characteristics of sludge from treatment plants in tomato processing industries. Food Bioprod Process 90: 224-234.

32. Sharma GP, Verma RC, Pathare PB (2005) Thin-layer infrared radiation drying of onion slices. J Food Eng 67: 361-366.

33. Rayaguru K, Routray W (2011) Microwave drying kinetics and quality characteristics of aromatic Pandanus amaryllifolius leaves. Int Food Res J 18: 1035-1042.

34. Motevali A, Minaei S, Khoshtaghaza MH (2011) Evaluation of energy consumption in different drying methods. Energ Convers Manag 52: 11921199. 